Int. J. Morphol.,

31(1):169-171, 2013

\title{
Anomalous Origin of the Circumflex Branch from the Right Coronary Artery
}

\author{
Origen Anómalo de la Rama Circunfleja \\ desde la Arteria Coronaria Derecha
}

Parvindokht Bayat*; Farhadi Masoud"; Ali Ghanbari*** Sedigheh Gannnnji-Harsini****

BAYAT, P.; MASOUD, F.; GHANBARI, A. \& GANJI-HARSINI, S. Anomalous origin of the circumflex branch from the right coronary artery. Int. J. Morphol., 31(1):169-171, 2013.

SUMMARY: Coronary anomalies are a group of congenital disorders. Most of the coronary anomalies are asymptomatic and benign but may cause myocardial ischemia and sudden death. Some of them are dangerous if they associate with other heart diseases. One of the congenital coronary anomalies is anomalous origin of the circumflex branch from the right coronary artery that is a rare congenital anomaly. We present a case of a 61-year-old man with history of hypertension, diabetes mellitus and hyperlipidemia. The coronary angiography reveals a circumflex branch from the right coronary artery.

KEY WORDS: Circumflex branch; Coronary artery; Anatomical variation; Congenital disorders.

\section{INTRODUCTION}

Coronary anomalies are a group of congenital disorders with highly variable pathophysiological mechanism and manifestation (Carvalho et al., 1993). The presence of anomalous coronary arteries observed about $1 \%$ of patients undergoing cardiac catheterization (Plastiras et al., 2008). Also we see the occurrence of coronary anomalies is $0.3-0.9 \%$ in patients without structural heart disease and significantly higher (3-36\%) in patients with structural heart defects (Carvalho et al.; Dabizzi et al., 1990).

From about 2500 patients that referred to hospital and educational center of Amir-Momenin for angiography of the coronary artery we see only 2 anomalies of the coronary arteries. So we find that about $0.08 \%$ of patients that referred to our educational center for angiography have coronary anomalies.

For these patients angiography was performed for another heart disease not only for their coronary anomalies because most of the coronary anomalies are asymptomatic (Angelina et al., 2003). Prognosis of coronary anomalies is depending on the proximal course of the anomalously arising coronary artery in relation to the great vessels. Their early detection and the exact delineation of their proximal course are crucial (Gavrielatos et al., 2007).

Circumflex branch (LCx) in normal hearts. Is an artery of the heart that courses the left part of the coronary sulcus, running first to the left and then to the right, reaching nearly as far as the posterior longitudinal sulcus. Branches the circumflex artery curves to the left around the heart within the coronary sulcus, giving rise to one or more diagonal or left marginal arteries (also called obtuse marginal branches $(\mathrm{OM})$ as it curves toward the posterior surface of the heart. It helps from the posterior left ventricular branch or posterolateral artery. The circumflex branch ends at the point where it joins to from to the posterior interventricular artery in ten percent of all cases, which lies in the posterior interventricular sulcus. In other $90 \%$ of all cases the posterior interventricular artery comes out of the right coronary artery. Structures supplied the LCx supplies the posterolateral left ventricle and the anterolateral papillary muscle. It also supplies the sinoatrial nodal artery in $38 \%$ of people (Samaredra et al., 2001).

This report presents a very unusual case of an anomalous origin of the circumflex branch (LCx) from the proximal right coronary artery (RCA).

* Department of Anatomy, Arak University of Medical Sciences, Arak, Iran.

** Fertility and Infertility Research Center, Kermanshah University of Medical Sciences, Kermanshah, Iran.

**** Student Research committee, Kermanshah University of Medical Sciences, Kermanshah, Iran. 


\section{CASE REPORT}

A 61-year-old male patient with history of hypertension, diabetes mellitus (DM) and hyperlipidemia (HLP) presented with retrosternal pain.

This man was referred for routine coronary angiography and also ECG was performed. Coronary angiography showed: LADA (Left Anterior Descending artery), proximal of this artery is occlusion but the rest of LADA has good retrograde filling from RCA; LCx, this artery originates from the proximal of the RCA and has good run off; RCA: well developed without significant stenosis; LMT (Left Main Trunk): total occlusion and without run off. Ejection fraction of this patient was normal (about 60\%) and her blood pressure was 145/90 (B.P: $145 / 90)$

\section{DISCUSSION}

Although interest in coronary arteries primarily focused on the debilitating effects disease has on their function, the generation of these vessels is truly a complex story in developmental biology and clearly plays a central role in the function of the adult structure. Cell lineage commitment and diversification, directed cell migration, control of epithelial/mesenchymal transition, and cell differentiation are some of the hallmarks in the development of coronary arteries (Reese et al., 2002).

The ectopic origin of the LCx is a well-recognized variant, which is considered the most common coronary anomaly and can be found in approximately 0.37 to $0.7 \%$ of all patients. The anomalous $\mathrm{LCx}$ most commonly arises from a separate ostium within the right sinus, or as a proximal branch of the RCA (Rozenman, 1993).

Although this anomaly is classified as benign and asymptomatic, a few cases of sudden death, myocardial infarction and angina pectoris in the absence of atherosclerotic lesion have been reported (Corrado et al., 1994).

Symptomatic carriers of anomalies like this case have 3 treatment options: medical treatment/observation, coronary angioplasty with stent deployment, and surgical repair. Despite the limitation of our current knowledge of such anomalies, intervention may be justified in some cases to prevent sudden death and improve the quality of life. Medical treatment (essentially with b-blockers) is probably as effective as restriction of activity (avoidance of severe exertion) in these patients (Maron \& Zipes, 2005).

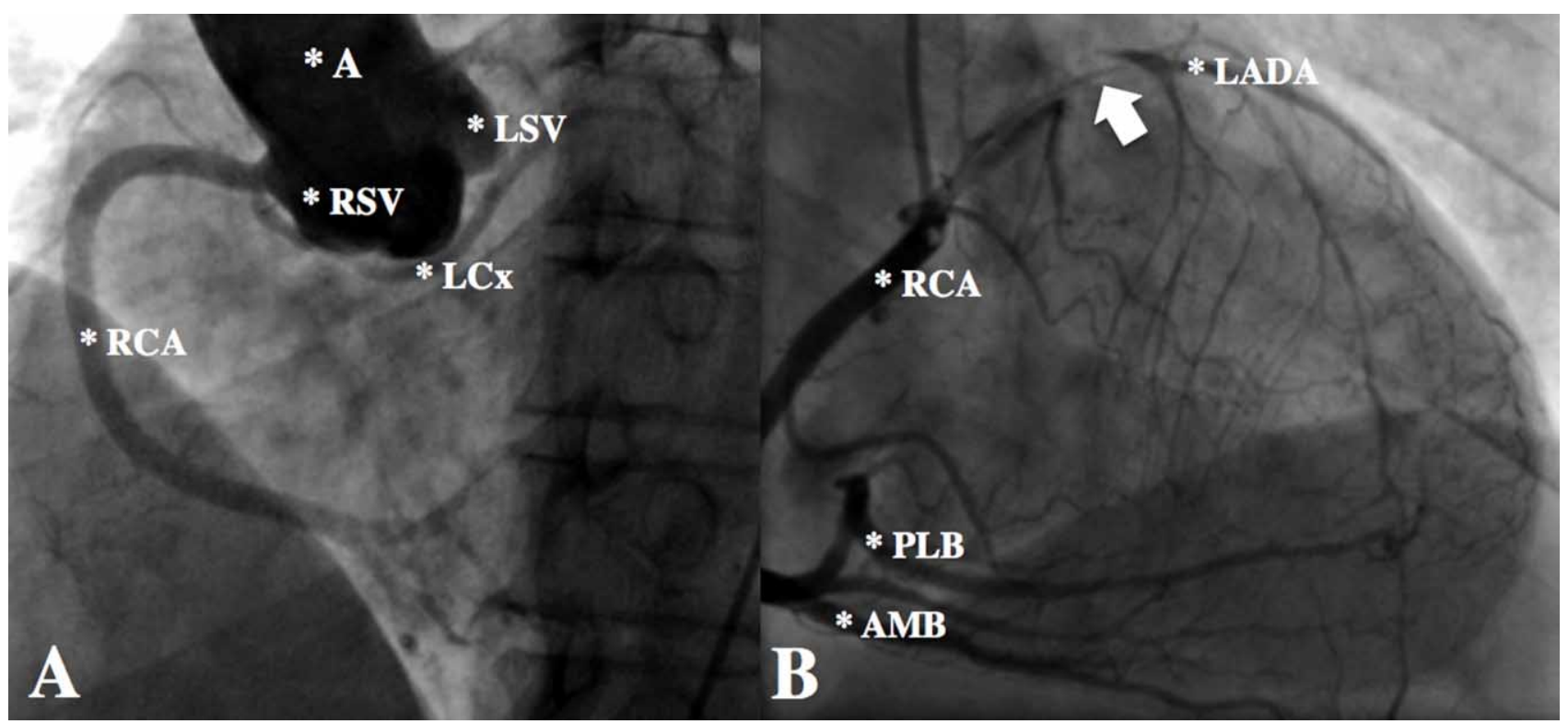

Fig. 1. The pictures show the anomalous and occlusions in the course of the arteries of heart. A) Originating of Left circumflex coronary artery (LCx) from Right coronary artery (RCA) near to Right sinus of valsalva (RSV); Aorta (A). B) Left anterior descending artery (LADA) has good retrograde filling from the RCA. In the normal cases the LADA is filling separately from the right coronary artery (RCA). Posterolateral branch (PLB) and Acute marginal branch (AMB). Withe arrow show the occlusion in left anterior descending artery. 
BAYAT, P.; MASOUD, F.; GHANBARI, A. \& GANJI-HARSINI, S. Origen anómalo de la rama circunfleja desde la arteria coronaria derecha. Int. J. Morphol., 31(1):169-171, 2013.

RESUMEN: Las anomalías coronarias son un grupo de trastornos congénitos. La mayoría de estas anomalías son asintomáticas y benignas, pero pueden causar isquemia miocárdica y muerte súbita. Algunas son peligrosas si se asocian con enfermedades cardiacas. Una de las anomalías coronarias congénitas corresponde al origen anómalo de la rama circunfleja desde la arteria coronaria derecha, que es poco frecuente. Se presenta un caso de un hombre de 61 años de edad con antecedentes de hipertensión arterial, diabetes mellitus e hiperlipidemia. La angiografía coronaria reveló una rama circunfleja que se originaba desde la arteria coronaria derecha.

PALABRAS CLAVE: Rama circunfleja; Arteria coronaria; Variación anatómica; Trastornos congénitos.

\section{REFERENCES}

Angelina, P.; Velasco, J. A.; Ott, D. \& Khoshnevis, G. R. Anomalous coronary artery arising from the opposite sinus: descriptive features and pathophysiologic mechanisms, as documented by intravascular ultrasonography. J. Invasive Cardiol., 15(9):50714, 2003.

Carvalho, J. S.; Silva, C. M.; Rigby, M. L. \& Shinebourne, E. A. Angiographic diagnosis of anomalous coronary artery in tetralogy of Fallot. Br. Heart J., 70(1):75-8, 1993.

Corrado, D.; Penelli, T.; Piovesana, P. \& Thiene, G. Anomalous origin of the left circumflex coronary artery from the right aortic sinus of valsalva and sudden death. Cardiovasc. Pathol., 3(4):269-71, 1994.

Dabizzi, R. P.; Teodori, G.; Barletta, G. A.; Caprioli, G.; Baldrighi, G. \& Baldrighi, V. Associated coronary and cardiac anomalies in the tetralogy of Fallot. An angiographic study. Eur. Heart J., 11(8):692-704, 1990.

Gavrielatos, G.; Letsas, K. P.; Pappas, L. K, Antonellis, I. \& Kardaras, F. Anomalous origin of the entire coronary system with separate ostia within the right sinus of valsalva: a rare congenital anomaly and a review of the literature. Cardiology, 107(3):209-12, 2007.

Maron, B. J. \& Zipes, D. P. Introduction: eligibility recommendations for competitive athletes with cardiovascular abnormalities-general considerations. J. Am. Coll. Cardiol., 45(8):1318-21, 2005.

Plastiras, C. S.; Kampessi, S. O.; Gotzamanidou, M. \& Kastanis, P. Anomalous origin of the left circumflex artery from the right coronary artery: a case report. Cases J., 1(1):336, 2008.

Reese, D. E.; Mikawa, T. \& Bader, D. M. Development of the coronary vessel system. Circ. Res., 91(9):761-8, 2002.

Rozenman, Y.; Schechter, D.; Gilon, D. \& Gotsman, M. S. Anomalous origin of the circumflex coronary artery from the right sinus of Valsalva as a cause of ischemia at old age. Clin. Cardiol., 16(12):900-1, 1993.
Samarendra, P.; Kumari, S.; Hafeez, M.; Vasavada, B. C. \& Sacchi, T. J. Anomalous circumflex coronary artery: benign or predisposed to selective atherosclerosis. Angiology, 52(8):5216, 2001.

\section{Correspondence to:}

Ali Ghanbari

Fertility and Infertility Research Center

Kermanshah University of Medical Sciences

P.O. Box 1568, Kermanshah

IRAN

Email: aghanbari@kums.ac.ir

Received: 24-08-2012

Accepted: 16-11-2012 